\title{
Angiotensin-(1-7) as a biomarker of childhood obesity: Is there a causal relationship?
}

\author{
Yoichi Nozato $^{1} \cdot$ Koichi Yamamoto ${ }^{1}$
}

Received: 11 April 2021 / Revised: 13 April 2021 / Accepted: 14 April 2021 / Published online: 21 June 2021

(c) The Japanese Society of Hypertension 2021

\section{Angiotensin-(1-7) as a product of ACE2}

The renin-angiotensin system (RAS) is a major regulator of cardiovascular and metabolic systems. During the last two decades, angiotensin converting enzyme (ACE) 2-angiotensin(1-7)-Mas was established as a counteraxis of the classical RAS pathway [1]. Angiotensin-(1-7) functionally antagonizes angiotensin II through its receptor, Mas. ACE2, identified as the homolog of ACE, plays a pivotal role in the endogenous production of angiotensin-(1-7) [2]. Substrates of ACE2 are not limited to those within the RAS and involve various peptides, including des-Arg9'-bradykinin (BK). The organprotective role of angiotensin-(1-7) on the cardiovascular, renal, endocrine, and skeletal muscle systems has been well recognized and discussed [1].

\section{Angiotensin-(1-7) and obesity}

The favorable effect of angiotensin-(1-7) on obesity and adipose function has been well elucidated using various rodent models, including pharmacological infusion or oral intake of angiotensin-(1-7), loss of function of ACE2 or MAS, and transgenic overexpression of angiotensin-(1-7) [3]. Increased circulating angiotensin-(1-7) improved glucose and lipid metabolism and alleviated the proinflammatory profile of adipose tissue in transgenic rats overexpressing angiotensin(1-7) [4].

Although the therapeutic effect of angiotensin-(1-7) on metabolism and obesity has been shown extensively in

Yoichi Nozato

yoichi.nozato@geriat.med.osaka-u.ac.jp

Koichi Yamamoto

kyamamoto@geriat.med.osaka-u.ac.jp

1 Department of Geriatric and General Medicine, Osaka University Graduate School of Medicine, Suita, Osaka, Japan experimental studies, data in terms of the causal relationship between physiological levels of angiotensin-(1-7) and obesity or subsequent metabolic disorder are limited, particularly in clinical studies [5].

\section{Obesity and fetal programming}

Obesity during childhood increases the risk of type 2 diabetes, hypertension, dyslipidemia, and cardiovascular diseases [6, 7]. Lifestyle issues such as excess caloric intake and reduced activities as well as genetic factors clearly contribute to the development of obesity. Childhood obesity is associated with a family history of obesity and cardiovascular and metabolic diseases [8]. Recently, maternal obesity has been widely recognized as a risk factor for pregnancy complications, including gestational diabetes, preeclampsia, and delivery of large-for-gestational-age infants, which cause low or high birth weights, leading to childhood obesity and an increased risk of future cardiovascular and metabolic diseases [9-11]. Increasing evidence from experimental and clinical studies indicates that prenatal stress, including intrauterine nutrient insufficiency, hypoxia, oxidative stress, and exposure to hormones, may program the further development of diseases, which is known as fetal programming [12]. A poor intrauterine environment with maternal obesity during pregnancy is associated with higher placental vascular dysfunction and placental inflammation, which could alter placental transporter activity and mitochondrial activity [13]. A few studies have demonstrated that the mechanism of programmed obesity is associated with appetite dysregulation and adipogenesis [11]. The exact mechanisms of how fetal programming events increase the risk of obesity remain unknown and are controversial.

\section{Obesity and angiotensin 1-7 in adolescents}

Recently, Fernandes et al. revealed that plasma angiotensin(1-7) and des- $\mathrm{Arg}^{9}$-BK metabolites can be novel biomarkers 
Fig. 1 Proposed hypothesis of the association between fetal programming and the ACE2angiotensin-(1-7)-Mas axis in the development of childhood obesity
Proposed hypothesis of the association between fetal programming and the ACE2-Angiotensin-(1-7)-Mas axis in the development of childhood obesity

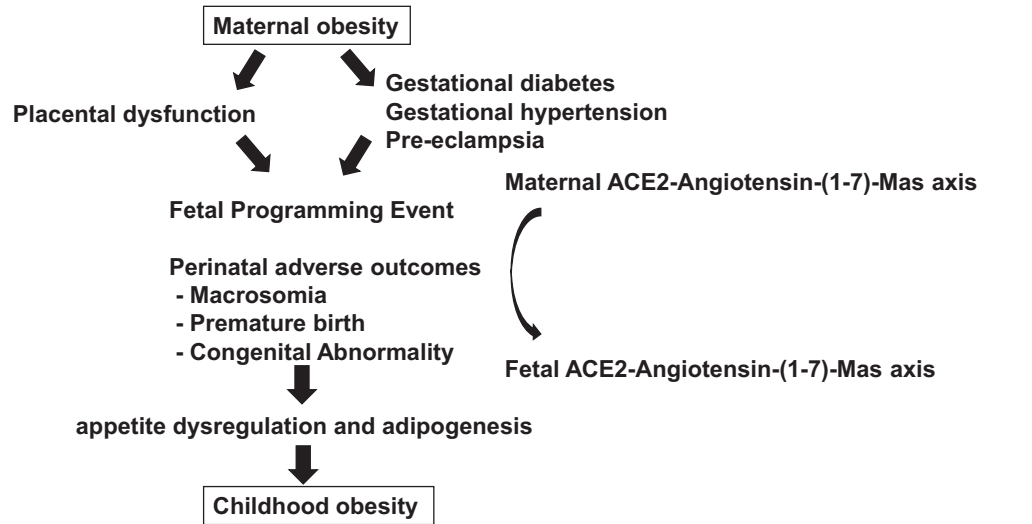

of obesity during childhood [14]. In 104 healthy adolescents aged 11-17 years without a history of hypertension and diabetes, BMI was inversely correlated with plasma levels of angiotensin-(1-7) and BK and positively correlated with angiotensin I and des-Arg ${ }^{9}-\mathrm{BK}$. Angiotensin-(1-7) and BK are also inversely correlated with HOMA, SBP, vasopressin, triglycerides, and CRP, suggesting relationships between the levels of these peptides and insulin resistance, hypertensive state, adiposity and systemic chronic inflammation [14]. Family history of obesity was higher in the groups with a higher BMI [14]. Given the potential favorable effect of angiotensin-(1-7) on obesity and adipose function, the authors concluded that plasma levels of angiotensin-(1-7), $\mathrm{BK}$ and des- $\mathrm{Arg}^{9}$-BK are potential biomarkers that determine the degree of obesity in adolescents.

Regarding the mechanisms involved in the altered levels of angiotensin-(1-7) and BK metabolites in obese adolescents, Fernandes et al. hypothesized that ACE2 activity, as an endogenous source of angiotensin-(1-7) production and des-Arg ${ }^{9}$-BK degradation, is reduced in obese adolescents; however, this hypothesis is inconclusive because plasma ACE2 activity was not detected in the present study [14]. Nevertheless, it should be noted that plasma ACE2 activity is not necessarily proportional to the net systemic activity of ACE2 for determining plasma angiotensin-(1-7) levels. Circulating ACE2 activity in humans may be a marker of CVD, with low levels in healthy individuals and increased levels in those with cardiovascular risk factors or diseases [15]. The classical RAS is recognized as a key signaling pathway in the pathology of fetal reprogramming, whereas a favorable impact of ACE2-angiotensin-(1-7) and Mas on fetal programming has currently been suggested [16]. Interestingly, a recent study demonstrated that preterm birth is associated with decreased fetal and maternal angiotensin(1-7) [17]. Another study demonstrated that obesity is associated with increased angiotensin II and decreased angiotensin-(1-7) among adolescents born prematurely
[18]. This could lead to a hypothesis that pathological fetal programming might attenuate the ACE2-angiotensin-(1-7)Mas axis in the offspring to induce future pathologic conditions (Fig. 1). Nevertheless, further studies are required to elucidate the actual causal relationship between obesity and the regulation of the ACE2-angiotensin-(1-7)-Mas axis in childhood. Additionally, other molecules, including ACE and neprilysin, are also involved in the metabolism of angiotensin and BK, and further evaluation should be conducted in relation to these molecules.

Finally, ACE2 is identified as the functional receptor of SARS coronavirus (SARS-CoV-1 and SARS-CoV-2) $[19,20]$. Because the recent COVID-19 pandemic is an emerging threat to global public health, the factors that regulate ACE2 expression or activities are of great interest. Given the potential involvement of ACE2 in the present study by Fernandes et al., further attention should be given to whether and how the regulation of ACE2 and its substrates would alter the health of adolescents, particularly in the context of obesity [14].

\section{Compliance with ethical standards}

Conflict of interest The authors declare no competing interests.

Publisher's note Springer Nature remains neutral with regard to jurisdictional claims in published maps and institutional affiliations.

\section{References}

1. Santos RAS, Sampaio WO, Alzamora AC, Motta-Santos D, Alenina $\mathrm{N}$, Bader M, et al. The ACE2/Angiotensin-(1-7)/MAS Axis of the Renin-Angiotensin System: Focus on Angiotensin-(1-7). Physiol Rev. 2018;98:505-53.

2. Vickers C, Hales P, Kaushik V, Dick L, Gavin J, Tang J, et al. Hydrolysis of biological peptides by human angiotensin-converting enzyme-related carboxypeptidase. J Biol Chem. 2002;277:14838-43.

3. Santos SH, Andrade JM. Angiotensin 1-7: a peptide for preventing and treating metabolic syndrome. Peptides. 2014;59:34-41. 
4. Santos SH, Fernandes LR, Pereira CS, Guimarães AL, de Paula AM, Campagnole-Santos MJ, et al. Increased circulating angiotensin-(1-7) protects white adipose tissue against development of a proinflammatory state stimulated by a high-fat diet. Regul Pept. 2012;178:64-70.

5. Rodrigues Prestes TR, Rocha NP, Miranda AS, Teixeira AL, Simoes ESAC. The anti-inflammatory potential of ACE2/angiotensin-(1-7)/Mas receptor axis: evidence from basic and clinical research. Curr Drug Targets. 2017;18:1301-13.

6. Juonala M, Magnussen CG, Berenson GS, Venn A, Burns TL, Sabin MA, et al. Childhood adiposity, adult adiposity, and cardiovascular risk factors. N. Engl J Med. 2011;365:1876-85.

7. Franks PW, Hanson RL, Knowler WC, Sievers ML, Bennett PH, Looker HC. Childhood obesity, other cardiovascular risk factors, and premature death. N. Engl J Med. 2010;362:485-93.

8. Corica D, Aversa T, Valenzise M, Messina MF, Alibrandi A, De Luca F, et al. Does family history of obesity, cardiovascular, and metabolic diseases influence onset and severity of childhood obesity? Front Endocrinol. 2018;9:187.

9. Godfrey KM, Reynolds RM, Prescott SL, Nyirenda M, Jaddoe VW, Eriksson JG, et al. Influence of maternal obesity on the long-term health of offspring. Lancet Diabetes Endocrinol. 2017;5:53-64.

10. Friedman JE. Developmental Programming of Obesity and Diabetes in Mouse, Monkey, and Man in 2018: Where Are We Headed? Diabetes. 2018;67:2137-51.

11. Desai M, Ross MG. Fetal programming of adipose tissue: effects of intrauterine growth restriction and maternal obesity/high-fat diet. Semin Reprod Med. 2011;29:237-45.
12. Bogdarina I, Welham S, King PJ, Burns SP, Clark AJ. Epigenetic modification of the renin-angiotensin system in the fetal programming of hypertension. Circ Res. 2007;100:520-6.

13. Gaillard R. Maternal obesity during pregnancy and cardiovascular development and disease in the offspring. Eur $\mathrm{J}$ Epidemiol. 2015;30:1141-52.

14. Fernandes FB, Fernandes AB, Febba ACS, Leite APO, Leite CA, Vitalle MSS, et al. Association of Ang-(1-7) and des-Arg(9)BK as new biomarkers of obesity and cardiometabolic risk factors in adolescents. Hypertens Res. 2021. online ahead of print.

15. Patel SK, Velkoska E, Burrell LM. Emerging markers in cardiovascular disease: where does angiotensin-converting enzyme 2 fit in? Clin Exp Pharm Physiol. 2013;40:551-9.

16. South AM, Shaltout HA, Washburn LK, Hendricks AS, Diz DI, Chappell MC. Fetal programming and the angiotensin-(1-7) axis: a review of the experimental and clinical data. Clin Sci. 2019; 133:55-74.

17. Chen YP, Lu YP, Li J, Liu ZW, Chen WJ, Liang XJ, et al. Fetal and maternal angiotensin (1-7) are associated with preterm birth. J Hypertens. 2014;32:1833-41.

18. South AM, Nixon PA, Chappell MC, Diz DI, Russell GB, Shaltout HA, et al. Obesity is associated with higher blood pressure and higher levels of angiotensin II but lower angiotensin-(1-7) in adolescents born preterm. J Pediatr. 2019;205:55-60. e51

19. Li W, Moore MJ, Vasilieva N, Sui J, Wong SK, Berne MA, et al. Angiotensin-converting enzyme 2 is a functional receptor for the SARS coronavirus. Nature. 2003;426:450-4.

20. Zheng YY, Ma YT, Zhang JY, Xie X. COVID-19 and the cardiovascular system. Nat Rev Cardiol. 2020;17:259-60. 